\title{
Tabela de pesos atómicos com quatro algarismos significativos *
}

A pedido do Comité para o Ensino da Química da IUPAC e em ligação com a comissão de Pesos Atómicos e Abundâncias Isotópicas da IUPAC, N.N. Greenwood e H.S. Peiser prepararam esta Tabela de Pesos Atómicos com quatro algarismos significaticos.

"Peso atómico" é o termo preferido por muitos químicos mas "massa média atómica relativa" é equivalente e preferida por outros. Desde 1961 que os valores aceites internacionalmente foram referenciados ao isótopo de ${ }^{12} \mathrm{C}$ para o qual o peso atómico é igual a exactamente 12. Os pesos atómicos são, pois, números, adimensionais, numericamente iguais às massas molares dos elementos expressas em grama por mole. Os valores tabelados de pesos atómicos aplicam-se aos elementos químicos na sua composição isotópica terrestre.

Vinte elementos têm um só isótopo que aparece na Natureza e os seus pesos atómicos foram determinados com muita precisão, sempre superior a uma parte por milhão. Contudo, muitos elementos têm mais do que um isótopo natural. As dificuldades experimentadas ao determinar a abundância relativa destes isótopos, bem como a sua variação natural limitam a precisão com que se pode citar a precisão do peso atómico de um elemento. Para elementos com composição isotópica variável, o peso atómico não é uma constante da Natureza mas deve ser visto como uma propriedade da amostra particular do elemento em estudo. Para a precisão de quatro algarismos indicada nesta tabela, os pesos atómicos podem ser vistos com segurança como constantes, embora sejam conhecidos geologicamente especimens altamente excepcionais para pelo menos $\mathbf{3 1}$ elementos nos quais a composição isotópica determina um peso atómico que difere do valor tabelado em mais do que a incerteza indicada.

É possível separar isótopos artificialmente. Por exemplo, amostras de hidrogénio que têm dois isótopos estáveis de massa atómica relativa 1,007 825 e 2,014 102 podem variar entre estes dois extremos, o hidrogénio que existe na Natureza tem sempre valores próximos de 1,0080 . Os valores de pesos atómicos dados na tabela não se aplicam a isótopos separados artificialmente e a outras amostras que tenham sido submetidas a processos que alterem apreciavelmente a composição isotópica dos elementos.

Muitos elementos, incluindo todos os de número atómico superior ao do bismuto, são radioactivos com isótopos que se transformam em outros elementos no decurso do tempo. O peso atómico de uma dada amostra de um tal elemento depende da velocidade relativa com a qual se decompõem os seus vários isótopos e, algumas vezes também, depende da origem radiogénica dessa amostra particular. Muitas amostras contêm um só radioisótopo de um dado elemento. Sem a identificação dos radioisótopos envolvidos e, sem o conhecimento das suas abundâncias relativas, se mais do que um está presente na amostra, não é possivel citar um peso atómico aproximado mesmo com quatro algarismos significativos. Consequentemente, nesta tabela, a massa atómica relativa de um dos isótopos é citada e identificada pelo seu número de massa em índice superior, precedido pelo seu símbolo químico. Esta espécie de listagem também se usa para vários elementos radioactivos conhecidos artificialmente de número atómico superior ao do urânio.

Os pesos atómicos dos elementos são revistos e apreciados pela Comissão de Pesos Atómicos e Abundâncias Isotópicas da IUPAC de dois em dois anos. Os seus relatórios bienais devem ser consultados para mais detalhes e elaboração. O relatório mais recente sobre "pesos atómicos dos elementos 1981" foi publicado em Pure and Applied Chemistry (1983), 55, 1101. É altamente improvável que os valores citados com quatro algarismos significativos sejam alterados em revisões subsequentes em mais do que as incertezas indicadas. As pequenas revisర̃es feitas pela comissão em 1983 estão incorporadas nesta tabela com quatro algarismos significativos, embora o relatório global da comissão para 1983 não esteja disponivel antes de 1984 ou 1985.

\section{TABELA DE PESOS ATÓMICOS COM QUATRO ALGARISMOS SIGNIFICATIVOS* \\ (referenciados à massa atómica relativa de ${ }^{12} \mathrm{C}$ igual a exactamente 12)}

Os valores citados nesta tabela têm precisão de \pm 1 , pelo menos, no quarto algarismo significativo, excepto para os cinco elementos para os quais estão indicadas incertezas maiores. Cada elemento que não tem um isótopo estável nem uma composição isotópica característica está representado nesta tabela por um dos radioisótopos do elemento habitualmente conhecidos identificado pelo seu número de massa (em indice superior precedendo o símbolo químico) e pela sua massa atómica relativa

\begin{tabular}{|clll|}
\hline $\begin{array}{c}\text { N. }{ }^{\circ} \\
\text { atómico }\end{array}$ & \multicolumn{1}{c|}{ Nome } & Símbolo & \multicolumn{1}{c|}{$A_{\mathrm{r}}$} \\
1 & hidrogénio & $\mathrm{H}$ & 1,008 \\
2 & hélior & $\mathrm{He}$ & 4,003 \\
3 & lítio & $\mathrm{Li}$ & $6,941 \pm 2$ \\
4 & berílio & $\mathrm{Be}$ & 9,012 \\
5 & boro & $\mathrm{B}$ & 10,81 \\
6 & carbono & $\mathrm{C}$ & 12,01 \\
7 & azoto (1) & $\mathrm{N}$ & 14,01 \\
8 & oxigénio & 0 & 16,00 \\
9 & fluor & $\mathrm{F}$ & 19,00 \\
10 & néon & $\mathrm{Ne}$ & 20,18 \\
\hline
\end{tabular}

* Folha distribuida na reunião do Comité para o Ensino da Química da IUPAC realizada em Londres em Julho de 1984. Tradução de Mariana P.B.A. Pereira. 


\begin{tabular}{|c|c|c|c|}
\hline N. ${ }^{\circ}$ Atómico & Nome & Símbolo & $\mathrm{Ar}$ \\
\hline 11 & sódio & $\mathrm{Na}$ & 22,99 \\
\hline 12 & magnésio & $\mathrm{Mg}$ & 24,31 \\
\hline 13 & aluminio & $\mathrm{Al}$ & 26,98 \\
\hline 14 & silicio & $\mathrm{Si}$ & 28,09 \\
\hline 15 & fósforo & $\mathbf{P}$ & 30,97 \\
\hline 16 & enxofre & $\mathrm{S}$ & 32,07 \\
\hline 17 & cloro & $\mathrm{Cl}$ & 35,45 \\
\hline 18 & árgon & $\mathrm{Ar}$ & 39,95 \\
\hline 19 & potássio & K & 39,10 \\
\hline 19 & cálcio & $\mathrm{Ca}$ & 40,08 \\
\hline 21 & escândio & $\mathrm{Sc}$ & 44,96 \\
\hline 22 & titânio & $\mathrm{Ti}$ & $47,88 \pm 3$ \\
\hline 23 & vanádio & V & 50,94 \\
\hline 24 & crómio & $\mathrm{Cr}$ & 52,00 \\
\hline 25 & manganês (2) & Mn & 54,94 \\
\hline 26 & ferro & $\mathrm{Fe}$ & 55,85 \\
\hline 27 & cobalto & Co & 58,93 \\
\hline 28 & niquel & $\mathrm{Ni}$ & 58,69 \\
\hline 29 & cobre & $\mathrm{Cu}$ & 63,55 \\
\hline 30 & zinco & $\mathrm{Zn}$ & $65,39 \pm 2$ \\
\hline 31 & gálio & $\mathrm{Ga}$ & 69,72 \\
\hline 32 & germânio & $\mathrm{Ge}$ & $72,59 \pm 3$ \\
\hline 33 & arsénio & As & 74,92 \\
\hline 34 & selénio & $\mathrm{Se}$ & $78,96 \pm 3$ \\
\hline 35 & bromo & $\mathrm{Br}$ & 79,90 \\
\hline 36 & cripton & $\mathrm{Kr}$ & 83,80 \\
\hline 37 & rubidio & $\mathrm{Rb}$ & 85,47 \\
\hline 38 & estrôncio & $\mathrm{Sr}$ & 87,62 \\
\hline 39 & itrio & $\mathbf{Y}$ & 88,91 \\
\hline 40 & zircónio & $\mathrm{Zr}$ & 91,22 \\
\hline 41 & nióbio & $\mathrm{Nb}$ & 92,21 \\
\hline 42 & molibdénio & Mo & 95,94 \\
\hline 43 & tecnécio & ${ }^{99} \mathrm{Tc}$ & 98,91 \\
\hline 44 & ruténio & $\mathrm{Ru}$ & 101,1 \\
\hline 45 & ródio & $\mathrm{Rh}$ & 102,9 \\
\hline 46 & paládio & Pd & 106,4 \\
\hline 47 & prata & $\mathrm{Ag}$ & 107,9 \\
\hline 48 & cádmio & Cd & 112,4 \\
\hline 49 & índio & In & 114,8 \\
\hline 50 & estanho & Sn & 118,7 \\
\hline 51 & antimónio & $\mathrm{Sb}$ & 121,8 \\
\hline 52 & telúrio & $\mathrm{Te}$ & 126,6 \\
\hline 53 & iodo & I & 126,9 \\
\hline 54 & xénon & $\mathrm{Xe}$ & 131,3 \\
\hline 55 & césio & Cs & 132,9 \\
\hline 56 & bário & $\mathrm{Ba}$ & 137,3 \\
\hline 57 & lantânio & $\mathrm{La}$ & 138,9 \\
\hline 58 & cério & $\mathrm{Ce}$ & 140,1 \\
\hline 59 & praseodimio & $\operatorname{Pr}$ & 140,9 \\
\hline 60 & neodimio & Nd & 144,2 \\
\hline 61 & promécio & ${ }^{45} \mathrm{Pm}$ & 144,9 \\
\hline 62 & samário & $\mathrm{Sm}$ & 150,4 \\
\hline 63 & európio & Eu & 152,0 \\
\hline 64 & gadolínio & Gd & 157,3 \\
\hline 65 & térbio & $\mathrm{Tb}$ & 158,9 \\
\hline 66 & disprósio & Dy & 162,5 \\
\hline 67 & hólmio & Ho & 164,9 \\
\hline 68 & érbio & $\mathrm{Er}$ & 167,3 \\
\hline 69 & túlio & $\operatorname{Tm}$ & 168,9 \\
\hline 70 & itérbio & $\mathrm{Yb}$ & 173,0 \\
\hline 71 & lutécio & $\mathrm{Lu}$ & 175,0 \\
\hline 72 & hafnio & Hf & 178,5 \\
\hline 73 & tântalo & $\mathrm{Ta}$ & 180,9 \\
\hline 74 & volfrâmio (3) & W & 183,9 \\
\hline 75 & rénio & $\mathrm{Re}$ & 186,2 \\
\hline 76 & ósmio & Os & 190,2 \\
\hline 77 & iridio & Ir & 192,2 \\
\hline 78 & platina & $\mathrm{Pt}$ & 195,1 \\
\hline 79 & ouro & $\mathrm{Au}$ & 197,0 \\
\hline 80 & mercúrio & $\mathrm{Hg}$ & 200,6 \\
\hline 81 & tálio & $\mathrm{Tl}$ & 204,4 \\
\hline 82 & chumbo & $\mathrm{Pb}$ & 207,2 \\
\hline
\end{tabular}

\begin{tabular}{|clcc|}
\hline N. ${ }^{\circ}$ Atómico & Nome & Símbolo & $\mathrm{Ar}$ \\
83 & bismuto & $\mathrm{Bi}$ & 209,0 \\
84 & polónio & ${ }^{210 \mathrm{Po}}$ & 210,0 \\
85 & astato $(4)$ & $210 \mathrm{At}$ & 210,0 \\
86 & rádon & $222 \mathrm{Rn}$ & 222,0 \\
87 & frâncio & ${ }^{223} \mathrm{Fr}$ & 223,0 \\
88 & rádio & $226 \mathrm{Ra}$ & 226,0 \\
89 & actínio & ${ }^{227} \mathrm{Ac}$ & 227,0 \\
90 & tório & $\mathrm{Th}$ & 232,0 \\
91 & protactínio & ${ }^{231 \mathrm{~Pa}}$ & 231,0 \\
92 & urânio & $\mathrm{U}$ & 238,0 \\
93 & neptúnio & ${ }^{237} \mathrm{~Np}$ & 237,0 \\
94 & plutónio & ${ }^{239} \mathrm{Pu}$ & 239,1 \\
95 & amerício & ${ }^{243} \mathrm{Am}$ & 243,1 \\
96 & cúrio & ${ }^{247} \mathrm{Cm}$ & 247,1 \\
97 & berquélio & $247 \mathrm{Bk}$ & 247,1 \\
98 & califórnio & $252 \mathrm{Cf}$ & 252,1 \\
99 & einsteinio & $252 \mathrm{Es}$ & 252,1 \\
100 & férmio & $257 \mathrm{Fm}$ & 257,1 \\
101 & mendelévio & $256 \mathrm{Md}$ & 256,1 \\
102 & nobélio & $259 \mathrm{No}$ & 259,1 \\
103 & lawrêncio & ${ }^{260} \mathrm{Lr}$ & 260,1 \\
& & & \\
\hline
\end{tabular}

(1) ou nitrogẹnio; (2) ou manganésio; (3) ou tungsténio; (4) ou astatinio.

* Preparada por N.N. Greenwood e H.S. Peiser, a pedido do Comité para o Ensino da Química da União Internacional de Química Pura e Aplicada (IUPAC) em colaboração com a Comissão de Pesos Atómicos e Abundâncias Isotópicas da IUPAC.

\section{NOTAS:}

1 - esta tabela foi distribuída, em inglês, a editores e livreiros em Julho de 1984.

2 - a tradução desta tabela, precedida de uma introdução simples, foi posta à venda durante o 7. ${ }^{\circ}$ Encontro Anual de química, sector de Educação, em Setembro de 1984. 